\title{
O Território Invisível: Quilombo São Roque "Os Filhos da Pedra Branca", Praia Grande, SC, Brasil
}

\author{
The Invisible Territory: Quilombo São Roque "The Children of the \\ White Stone", Praia Grande, SC, Brazil
}
El Territorio Invisible: Quilombo São Roque "Los Hijos de la Piedra Blanca", Praia Grande, SC, Brasil

Le Territoire Invisible: Quilombo São Roque "Les enfants de la pierre blanche", Praia Grande, SC, Brésil

Gabriela Mariane dos Santos Carmo ${ }^{1}$, Naiara Machado da Silva ${ }^{2}$ e Aline Reis Calvo Hernandez ${ }^{3}$

\footnotetext{
${ }^{1}$ Graduada em Gestão de Turismo pelo Instituto Federal Catarinense, Sombrio, SC, Brasil. Aluna especial no Programa de Pós-Graduação em Ambiente e Sustentabilidade da Universidade Estadual do Rio Grande do Sul, São Francisco de Paula, RS, Brasil.

E-mail: gabriellamscarmo@gmail.com

${ }^{2}$ Mestranda no Programa de Pós-Graduação em Ambiente e Sustentabilidade da Universidade Estadual do Rio Grande do Sul, São Francisco de Paula, RS, Brasil.

\section{E-mail: naimss@gmail.com}

${ }^{3}$ Graduada em Psicologia e mestra em Educação pela pela Pontifícia Universidade Católica do Rio Grande do Sul, Porto Alegre, RS, Brasil, Doutora em Psicologia Social e Metodologia pela Universidad Autónoma de Madrid, Madri, Espanha. Atualmente é Professora Adjunta da Universidade Federal do Rio Grande do Sul, Porto Alegre, RS, Brasil, na Faculdade de Educação, Departamento de Estudos Básicos e líder do grupo de pesquisa Psicologia Política, Educação e Histórias do Presente; Professora Colaboradora do Programa de Pós-Graduação em Ambiente e Sustentabilidade e pesquisadora do grupo de pesquisa Observatório de Políticas e Ambiente da Universidade Estadual do Rio Grande do Sul, São Francisco de Paula, RS, Brasil. É editora associada da Revista de Psicologia Política e vice-coordenadora do grupo de trabalho em Psicologia Política da Associação Nacional de Pesquisa e Pós-graduação em Psicologia, biênio 2018-2020.
} 
Resumo

\section{Abstract}

Este artigo discute as concepções de território e territorialidade da comunidade quilombola São Roque. O recorte geográfico da pesquisa são as terras da comunidade rural, formada por descendentes de escravos, remanescentes de São Roque, localizada no extremo sul do estado de Santa Catarina, limítrofe ao estado do Rio Grande do Sul. São Roque é cenário do impasse socioambiental oriundo da sobreposição das terras pertencentes historicamente à comunidade afrodescendente a partir da implementação dos Parques Nacionais de Aparados da Serra e Serra Geral. A discussão embasa-se em estudos desenvolvidos sobre a comunidade, sua identidade, seus saberes situados e emergentes, dados secundários ou metadados, a partir de diferentes abordagens sobre território e territorialidade. $\mathrm{O}$ artigo propõe-se a dar visibilidade às comunidades quilombolas, em especial à comunidade São Roque, a fim de ampliar o debate em torno da luta e da memória política dessas populações pelo direito à terra, além de contribuir nas discussões acerca dos processos agrários brasileiros que são responsáveis pelos territórios invisíveis em relação ao fomento das políticas públicas nacionais.

Palavras-Chave: Território; Territorialidade; Identidade Quilombola; Memória Política; Aparados da Serra.

This article discusses the territorial and territorial conceptions of the quilombola community São Roque. The geographical coverage of the research is the rural community, formed by descendants of slaves, remnants of São Roque, located in the extreme south of the state of Santa Catarina, bordering the state of Rio Grande do Sul. São Roque is the scenario of the socioenvironmental impasse of the overlapping of lands belonging historically to the Afrodescendant community from the implementation of the National Parks of Aparados da Serra and Serra Geral. The discussion is based on studies developed about the community, its identity, its situated and emerging knowledge, secondary data or metadata, from different approaches on territory and territoriality. The article proposes to give visibility to the quilombola communities, in particular to the São Roque community, in order to broaden the debate about the struggle and the political memory of these populations for the right to the land, besides contributing in the discussions about the Brazilian agrarian processes which are responsible for the invisible territories in relation to the promotion of national public policies.

Keywords: Territory; Territoriality; Quilombola Identity; Political Memory; Aparados da Serra. 
Resumen

Resumé
Este artículo discute las concepciones de territorio y territorialidad de la comunidad quilombola São Roque. El recorte geográfico de la investigación son las tierras de la comunidad rural, formada por descendientes de esclavos, remanentes de São Roque, ubicada en el extremo sur del estado de Santa Catarina, limítrofe al estado de Rio Grande do Sul. São Roque es escenario del impasse socioambiental oriundo de la superposición de las tierras pertenecientes históricamente a la comunidad afrodescendiente a partir de la implementación de los Parques Nacionales de Aparados da Serra y Serra Geral. La discusión se basa en estudios desarrollados sobre la comunidad, su identidad, sus saberes situados y emergentes, datos secundarios o metadatos, a partir de diferentes enfoques sobre territorio y territorialidad. El artículo se propone dar visibilidad a las comunidades quilombolas, en especial a la comunidad São Roque, a fin de ampliar el debate en torno a la lucha y la memoria política de esas poblaciones por el derecho a la tierra, además de contribuir en las discusiones sobre los procesos agrarios brasileños que son responsables de los territorios invisibles en relación al fomento de las políticas públicas nacionales.

Palabras Clave: Territorio; Territorialidad; Identidad Quilombola; Memoria política; Aparados de la Sierra.

Cet article porte sur le territoire des conceptions et de la communauté de territorialité quilombo São Roque. Le schéma géographique de la recherche sont les terres de la communauté rurale, formée par les descendants d'esclaves, des restes de San Roque, situé dans l'État méridional de Santa Catarina, qui borde l'État de Rio Grande do Sul. San Roque met l'impasse environnementale découlant le recouvrement des terres appartenant historiquement à la communauté afro-descendant de la mise en œuvre des Aparados parcs nationaux de la Serra et de la Serra Geral. La discussion a été fondée sur des études développées sur la communauté, son identité, sa place et les nouvelles connaissances, les données secondaires ou des métadonnées de différentes approches sur le territoire et la territorialité. L'article propose de donner une visibilité aux communautés quilombos, en particulier la communauté de San Roque, afin d'élargir le débat sur la lutte et la mémoire politique de ces populations pour les droits fonciers et de contribuer aux discussions sur les processus agricoles brésiliens qui sont responsables des territoires invisibles par rapport à la promotion des politiques publiques nationales.

Mots-Clés: Territoire; Territorialidade; Identité Quilombola; Mémoire Politique; Aparados da Serra. 


\section{Introdução}

0 presente artigo discute as concepções de território e territorialidade dos remanescentes do quilombo São Roque na localidade definida como Pedra Branca, situada entre a região dos Campos de Cima da Serra e a planície costeira, que se caracteriza pelas escarpas da Serra Geral e faz fronteira com os estados de Santa Catarina e Rio Grande do Sul. A pesquisa se utiliza de dados secundários, por meio de uma revisão bibliográfica em estudos já desenvolvidos sobre a comunidade, como o importante relatório social e antropológico elaborado pelo Núcleo de Estudos sobre Identidade e Relações Interétnicas (NUER), da Universidade Federal de Santa Catarina (UFSC), publicado no ano de 2006.

O impasse socioambiental no qual a comunidade São Roque se encontra explicita-se a partir da sua autoidentificação étnica e do reconhecimento do território, delimitado no ano de 2007 pelo Instituto Nacional de Colonização e Reforma Agrária (INCRA), no qual parte do território está sobreposta pelas unidades de conservação integral, Parque Nacional de Aparados da Serra (PNAS) e Serra Geral (PNSG), atualmente administrados pelo Instituto Chico Mendes de Conservação da Biodiversidade (ICMBio). 0 seu reconhecimento foi resultado da mobilização coletiva reivindicatória, tanto por parte da organização da comunidade quanto pelo incentivo da Coordenação Estadual do Movimento Negro Unificado (MNU/SC; Spaolonse, 2013). O conflito está associado à disputa pela posse de terras e à regularização fundiária na região, o que se constitui de múltiplos capítulos, entre avanços e retrocessos, e envolve diversos grupos de interesse. Constituiu-se, assim, um impasse complexo e multifacetado, que se relaciona diretamente à luta da comunidade pela permanência no território, ao reconhecimento legal da propriedade da terra, ao acesso às políticas públicas do Programa Brasil Quilombola (PBQ) e ao espaço de diálogo sobre o modelo de conservação ambiental definido pelas Unidades de Conservação a partir do ponto de vista e da vivência da comunidade tradicional.

Inicialmente, abordam-se aspectos históricos da formação de quilombos e, em especial, da comunidade quilombola São Roque, a fim de contextualizar sua trajetória histórica e suas relações territoriais com a autoidentificação "Filhos da Pedra Branca". Caracteriza-se o conflito e os aspectos negligenciados pelas entidades ambientais e jurídicas durante o processo burocrático de reconhecimento e regularização do território quilombola. Nesse estudo, destacase a relevância da representação social com ênfase na ancestralidade negra, relacionada à opressão histórica sofrida pela comunidade e seu esforço coletivo para ocupar, usar, controlar e se identificar com o ambiente no qual desenvolveu a sua territorialidade e o sentimento de pertencimento (Little, 2002). Interdisciplinarmente, traz-se a discussão do presente artigo, a partir de diferentes abordagens sobre território e territorialidade, por meio de autores que se propuseram a discutir as transformações do espaço geográfico, como caráter político-econômico e como caráter simbólico-cultural.

Produzido a partir da disciplina de Psicologia Política, Ação Pública e Mudança Social do Mestrado em Ambiente e Sustentabilidade da Universidade Estadual do Rio Grande do Sul (UERGS), campus São Francisco de Paula, o artigo pretende dar visibilidade às comunidades quilombolas, em especial à comunidade São Roque, ampliando o debate em torno da luta e da memória política destas populações pelo direito à terra (a memória política, segundo Lifschitz (2014), como um contexto de memória com temporalidade, intencionalidade e enunciado). 
Promovem-se, assim, discussões sobre os processos agrários brasileiros que são responsáveis pelos territórios invisíveis em relação ao fomento das políticas públicas nacionais.

\section{Breve histórico da Comunidade Quilombola: formação de território}

As diversas leituras e historicidades explicitam a escravidão no Brasil como um processo de longa duração, sendo o último país do mundo a abolir legalmente a escravatura negra, no ano de 1888, com a Lei Áurea. De acordo com Reis (1996), estima-se que quatro milhões de africanos escravizados chegaram ao país, intensificando o tráfico de escravos e constituindo o comércio de mão de obra barata de todo o período colonial. Em contraponto ao sistema escravagista que perdurou no país durante três séculos, surgiram as organizações quilombolas como forma de resistência. Segundo Massolla e cols. (2015:284), “A imagem socialmente difundida dos quilombos no Brasil é bastante conhecida: um grupo de escravos fugidos do cativeiro que se congregam em região erma, pouco habitada, e vivem no isolamento, organizando-se em costumes parcial ou totalmente herdados de suas tradições africanas." Quilombo por si só é resistência à escravidão, pois a invisibilidade negra no Brasil é historicamente relacionada à denominada ideologia do branqueamento (Leite, 1991).

A história da comunidade São Roque tem sua origem vinculada à economia escravagista no sul do Brasil. A partir de documentação histórica, dados de 1850 permitem aferir que mais de um terço da população dos Campos de Cima da Serra, onde se constituiu o município de São Francisco de Paula, era escrava. "É provável, portanto, que, na primeira metade do século XIX, com uma população bem reduzida e concentrada em grandes latifúndios, o trabalho escravo tenha sido a única forma de trabalho não familiar na região." (Fernandes e cols., 2006:142). Nesse contexto, a comunidade surgiu por meio da dinâmica social e territorial que se estabelecia à época entre as regiões da serra, com campo e pecuária, e do litoral, onde fazendeiros realizavam as atividades agrícolas na planície do rio Mampituba. Situado ao redor da localidade Roça da Estância, este era o local para onde os escravos eram enviados a fim de trabalharem no cultivo da terra. Durante os trajetos pelas escarpas da Serra Geral, e que após, no final do século XIX, tornaram-se caminhos de tropas, eles encontravam pontos onde se refugiavam e articulavam sistemas e estratégias de fugas. Inicia-se o Campo dos Pretos, território de resistência negra e de outros pequenos grupos populacionais (Fernandes e cols., 2006). Na sequência, conforme relata o quilombola Afonso Pereira dos Santos Filho: "Foi escrito a carta aquela libertação, mas tinha pessoas aquelas que não tinha como viver, ficou desorientado, viver onde, eles vivia por exemplo na casa do senhor, lá ao redor, nos ranchinho de xaxim, daí comendo aquelas migalha que eles dava e muitos ficaram encostado, morreram de velho ali. Outros, vamos dizer, que vinham para um lugar desses aqui, viveram a vida assim." (Aguiyrre \& Cardoso, 2008).

Conforme Fernandes e cols. (2006:155), “[...] as famílias que hoje vivem na comunidade quilombola São Roque não apenas identificam suas origens com o regime escravista [...] mas, sobretudo, reconstroem sua historicidade através de narrativas que contêm elaboradas 
genealogias e referências precisas." Segundo o Relatório Antropológico dos autores, através de levantamentos sobre a memória genealógica da comunidade São Roque, foi possível encontrar a descendência quilombola e suas relações de parentescos, as quais se conectam com os ascendentes escravizados pelas famílias dos fazendeiros dos Campos de Cima da Serra. Além da autoidentificação com os seus antepassados, a relação sócio-histórica da comunidade e suas memórias, a construção social do território da comunidade São Roque se dá por meio do sistema de grotas, espaços de residência e subsistência. Nessa forma de organização, de acordo com os autores, cada família ocupava uma grota das encostas da serra, sempre banhadas por uma sanga, dentro do bioma Mata Atlântica. Segundo Spaolonse (2013:37), dispostas ao longo dos rios, cujos vales organizam o território, essas grotas têm como elemento central e simbolicamente unificador a Pedra Branca, topônimo que nomeia a localidade onde vive a comunidade São Roque e remete também a um tipo de autoidentificação territorial, "[...] uma vez que os quilombolas acionam a categoria de "filhos da Pedra Branca" para se diferenciarem daqueles moradores "de fora", que posteriormente vieram a se instalar na localidade, expressando o sentimento de pertença ao lugar." Sendo assim, compreender a historicidade de seus antepassados, por meio das narrativas, é compreender as relações sociais construídas ao longo do tempo, seus modos de organização, identidade, pertencimento e reconhecimento de sua territorialidade.

\section{Referencial Teórico}

Território relaciona-se intrinsecamente a poder. Como destaca Haesbaert (2004), o território configura-se a partir de relações de poder, seja o poder mais estrito, no sentido de dominação, seja em um sentido mais amplo, o simbólico. Para o autor, contudo, não se deve fazer uma distinção rígida entre território como dominação (material) e território como apropriação (simbólica), para se apreender a complexidade e a riqueza da multiterritorialidade em que estamos imersos. A partir das abordagens de diversos autores, ele considera que essas duas dimensões se configuram no território, que "(...) desdobra-se ao longo de um continuum que vai da dominação político-econômica mais 'concreta' e 'funcional' à apropriação mais subjetiva e/ou 'cultural-simbólica'." (Haesbaert, 2004:95-96).

Para Haesbaert (2007), o território surge, desde sua origem, com uma dupla conotação, material e simbólica, visto que o próprio termo, etimologicamente, aparece tão próximo de terra-territorium quanto de terreo-territor (terror, aterrorizar). Relaciona-se, desse modo, tanto à dominação jurídico-política da terra quanto à inspiração do terror, do medo “(...) especialmente para aqueles que, com esta dominação, ficam alijados da terra, ou no 'territorium' são impedidos de entrar. Ao mesmo tempo, por outro lado, podemos dizer que, para aqueles que têm o privilégio de plenamente usufruí-lo, o território pode inspirar a identificação (positiva) e a efetiva 'apropriação'." (Haesbaert, 2007:20). Contudo, como alerta Milton Santos (1999:21), a noção de poder não deve ser considerada somente a partir do Estado, pois, "A gestão do território, a regulação do território, são cada vez menos possíveis pelas instâncias ditas políticas 
e passam a ser exercidas pelas instâncias econômicas." Nessa perspectiva, a economia se realiza pela política, de modo que o papel central passa a ser exercido pelos agentes econômicos hegemônicos.

Segundo Haesbaert (2007), se, para o capitalista, cujo recurso é um meio para obter um fim (a acumulação e o lucro), podendo abstrair-se da identificação com o espaço em que estes são realizados, para os "hegemonizados" o território adquire muitas vezes tamanha força que combina com intensidades iguais a funcionalidade (recurso) e a identidade (símbolo). Nessa perspectiva, o território relaciona-se também à identidade, "toma aí todo o sentido que lhe foi atribuído por séculos de civilização campesina: ele é, ao mesmo tempo, raiz e cultura." (Bonnemaison, 2012:290-291). Para Haesbaert (2007:21), na condição de "espaço-tempo vivido", o território possui caráter "[...] múltiplo, 'diverso e complexo', ao contrário do território 'unifuncional' proposto e reproduzido pela lógica capitalista hegemônica, especialmente através da figura do Estado territorial moderno [...]." Na sua visão, como defensor de uma lógica territorial padrão, este Estado não admite outras formas de ordenação e, portanto, a multiplicidade/sobreposição de jurisdições e/ou de territorialidades.

Compreendida como a qualidade que o território adquire de acordo com a sua utilização ou apreensão pelo ser humano, a territorialidade, segundo Haesbaert (2007), pode ser tratada num sentido mais amplo do que território, visto que, embora ambos contenham uma dimensão simbólica, a territorialidade não está necessariamente condicionada a uma dimensão materialconcreta, condição que se verifica no caso do território. Na perspectiva de Haesbaert (2007), as concepções de territorialidade devem estar sempre associadas a concepções de território correspondentes. Comparando essas leituras, ele identifica desde a territorialidade como uma concepção mais ampla do que território até a territorialidade como algo mais restrito, que corresponderia a uma simples "dimensão" do território, passando pela abordagem que distingue claramente territorialidade e território.

Na concepção de Saquet (2009:83), o território e a territorialidade são multidimensionais e inerentes à vida na natureza e na sociedade e as territorialidades estão intimamente ligadas a cada lugar, pois, ao mesmo tempo em que elas lhe dão identidade, são também influenciadas pelas condições históricas e geográficas. Nessa relação, deve-se considerar a processualidade histórica e relacional, as diversidades e unidades em cada relação espaço-tempo-território. “0 território é produto social e condição. A territorialidade também significa condição e resultado da territorialização. 0 território é o conteúdo das formas e relações materiais e imateriais, do movimento, e significa apropriação e dominação, também material e imaterial, em manchas e redes." (Saquet, 2009:90).

0 processo de apropriação de um território pode assumir uma dimensão afetiva, derivada das práticas espacializadas dos distintos grupos, conforme referido por Santos (1998:251): "Neste sentido o conceito de território vincula-se a uma geografia que privilegia os sentimentos e simbolismos atribuídos aos lugares. Apropriação passa a associar-se à identidade de grupos e à afetividade espacial.".

As comunidades tradicionais têm a sua existência baseada nas relações específicas de sociabilidade, territorialização e percepção dos seus direitos, e que, entretanto, experimentam as formas "invisíveis" da violência do campo. Essa "invisibilidade", segundo estudos de José de Souza Martins, é fruto da conjunção entre desrespeito aos Direitos Humanos, falta de juridicialização da questão agrária e a expansão lógica capitalista ao campo que reedita a noção de fronteiras e pertencimento, ao tratar a violência do campo, no Brasil (Silva, 2006). 0 que nos 
impulsiona à reflexão em relação à invisibilidade social e política da comunidade tradicional frente aos segmentos sociais e jurídicos.

\section{Ressignificando o Território: análises e concepções sobre a territorialidade da Comunidade Quilombola São Roque}

Os conflitos que envolvem a Comunidade Quilombola São Roque (Pedra Branca) intensificaram-se a partir da criação e ampliação dos Parques Nacionais de Aparados da Serra e Serra Geral, que são áreas protegidas segundo o propósito da natureza intocável e com a pretensão de salvaguardar o espaço natural da ação humana; de modo geral, configuram espaço "[...] associado à proteção da natureza para usufruto de seus valores (naturais, estéticos, culturais e éticos) pelas gerações atuais e futuras." (MILANO, 1997:95 apud AMARAL, 1998:1415). Nesse processo, foram desconsideradas as ocupações humanas, em sua grande parte, comunidades tradicionais já existentes nestes territórios. Comunidades, estas, que construíram, por meio de sua historicidade e cultura, forte vínculo com o território em que vivem. De acordo com Spaolonse (2013:41-42), a partir da criação das Unidades de Conservação de Proteção Integral, interditando a ocupação e a interferência humana direta, e "[...] da desconsideração da possibilidade de existência de uma relação de interdependência desenvolvida por um grupo historicamente invisibilizado com aquele ambiente biofísico, as famílias que viviam há mais de século na região passaram a ser tidas como 'ilegais' e suas práticas de subsistência qualificadas como 'crime ambiental'."

Segundo o Sistema Nacional de Unidades de Conservação (SNUC), instituído pela Lei no 9.985, de 18 de julho de 2000, a categoria de proteção integral de unidades de conservação não comporta a ocupação humana. Essa mesma lei, no artigo 11, § 1ํㅡ, prevê que os ocupantes devem ser removidos, tendo as suas propriedades e/ou posses indenizadas. Contudo, conforme art. 68 do Ato das Disposições Constitucionais Transitórios (ADCT), assegura-se aos remanescentes quilombolas a propriedade definitiva das terras que estejam ocupando. Logo, a Constituição Federal de 1988 e o decreto 4.887/2003, que regulamentou o procedimento para identificação, reconhecimento, delimitação, demarcação e titulação das terras ocupadas por remanescentes das comunidades dos quilombos, bem como as Instruções Normativas N16/2003 e N20/2005, fazem referências diretas à relação de identidade e ao direito dos quilombolas sobre o seu território. Assim, a partir dessa regulamentação, os integrantes da comunidade organizaram-se para criar a Associação Remanescente de Quilombos de São Roque, no ano de 2003, que, conforme Fernandes e cols. (2006:135), “[...] possibilitou a centralização das discussões dos moradores e a organização de suas demandas num espaço único e ativo de interlocução com as esferas públicas e estatais." Segundo os autores, essas articulações resultaram da experiência dos moradores na condução de projetos de continuidade que já vinham sendo traçados extraoficialmente, podendo-se destacar dois momentos anteriores em que a comunidade São Roque se organizou com vistas a reivindicar direitos: a primeira, demandando políticas e 
donativos perante o poder público municipal e, a segunda, por meio de ação conjunta da Igreja Católica com comunidades vizinhas, que se opunham à construção de uma barragem que inundaria a região. Contudo, limitações como a escassez de documentos oficiais relativos a São Roque têm dificultado o reconhecimento efetivo dos direitos de seus integrantes. Conforme Fernandes e cols. (2006:140): "A principal dificuldade enfrentada para se reconstruir a história dos quilombos que se constituíram - durante a Colônia ou Império - principalmente como lugar de destino de escravos fugidos, reside no fato de que este tipo de organização social tinha o anonimato como parte de sua estratégia de sobrevivência." Assim, os documentos policiais passaram a constituir as principais fontes históricas para os quilombos. Fontes que, geradas a partir de situações de enfrentamento, mostraram-se escassas, no caso de São Roque, em função das péssimas condições da força policial na região e da sua limitada atuação, segundo os autores.

Uma vez que o Estado brasileiro, como detentor dos Parques Aparados da Serra e Serra Geral, trata as comunidades tradicionais, terras quilombolas, "reduzidas a sua base física", sem considerar a sua historicidade e pertencimento sócio-político (Furlan, 2000), faz-se indissociável reconhecer os termos de "multiterritorialidade e multiculturalidade" das diferenças humanas (Haesbaert, 2004). De acordo com Leite (1991:40-41):

0 território seria, portanto, uma das dimensões interétnicas, uma das referências do processo de identificação coletiva. Imprescindível e crucial para a própria existência do social. Enquanto tal, pode ser visto como parte de uma relação, como de um jogo. Desloca-se, transforma-se, é criado e recriado, desaparece e reaparece. Como uma das peças do jogo de alteridade, é também e principalmente contextual. No caso dos grupos étnicos, a noção de território parece ser tão ambígua como a própria condição dos grupos e talvez seja justamente o que acentua o seu valor defensivo.

Segundo Silva (2006: 276), "o território e sua objetivação, a territorialidade, dependem de práticas específicas dos grupos que se relacionam com ele, uma vez que sob um território estão sobrepostas muitas territorialidades." Logo, "[...] a territorialidade pode ser entendida como determinadas práticas expressas material e simbolicamente, em um dado território, por um determinado grupo social" (Lobato Correa, 1994:252), ou seja, território como híbrido e que se define pela inter-relação entre materialidade e imaterialidade (seu uso).

Sobre a temática, ressalta-se o áudio visual desenvolvido pelo Instituto do Patrimônio Histórico e Artístico Nacional (IPHAN), denominado "Documentário - Comunidade São Roque Referências Culturais Quilombolas". Destinado a valorizar a voz da comunidade com as narrativas sobre o tempo dos escravos e sua historicidade, o material apresenta a forma de ocupação, divisão de terras, identidade, cultura e sentimento de pertencimento da comunidade em relação ao espaço identitário. Em sua fala, um dos moradores mais idosos da comunidade, Afonso Pereira dos Santos Filho, sobre as fronteiras étnicas e do direito a um território exclusivo, afirma: “Aqui chama-se Pedra Branca, São Roque, né. Aqui a gente conheceu toda vida como Pedra Branca e depois o padroeiro agora é São Roque, então uns tratam como Pedra Branca, uns tratam como São Roque, mas é uma coisa só." (Aguiyrre, Cardoso, 2008). Na visão dessa comunidade quilombola, o território, constitui-se em espaço identitário do grupo ou de pertencimento, e por meio da sua memória e das relações de parentesco estabelecidas entre si, eles reconhecem a sua referência histórica de quilombo e herança das terras e garantias ao reconhecimento jurídico de sua propriedade. 
Pertencemos a um território, não o possuímos, guardamo-lo, habitamo-lo, impregnamos-no dele. Além disto, os viventes não são os únicos a ocupar o território, a presença dos mortos marca-o mais do que nunca com o signo do sagrado. Enfim, o território não diz respeito apenas à função ou ao ter, mas ao ser. Esquecer este princípio espiritual e não material é se sujeitar a não compreender a violência trágica de muitas lutas e conflitos que afetam o mundo de hoje: perder seu território é desaparecer. (Bonnemaison \& Cambrezy, 1996:4 citado por Haesbaert, 2004:73).

Identifica-se que a solidariedade e a reciprocidade marcam as relações entre os integrantes da Comunidade Quilombola São Roque, que desenvolveu uma territorialidade repleta de significações neste território que, desde tempos remotos, abrigou seus ancestrais, notadamente no período em que vigorou a escravidão de africanos no Brasil. Como referido em Fernandes e cols. (2006), trata-se de "[...] uma comunidade que mantém como referência sua relação histórica com o tempo dos escravos [grifo do autor]." Representativo disso, é o sistema tradicional de divisão territorial na comunidade, onde, ainda hoje, a distribuição espacial das famílias conserva parâmetros construídos no "tempo dos escravos", no qual os Senhores Nunes, Monteiro e Fogaça dominavam tais terras.

Essas configurações são apresentadas no estudo de Fernandes et al (2006) sob a forma de um diagrama elaborado a partir de entrevistas com membros da comunidade, no qual são identificadas relações de parentesco entre cinco gerações, incluindo informações sobre os escravos dos Senhores Nunes, Monteiro e Fogaça, seus locais de residência, seus descendentes e sobre as alianças matrimoniais estabelecidas. Segundo os autores, os escravos e seus descendentes constituíram-se enquanto comunidade ainda no século XIX, assim que se instalaram na região. E a distribuição espacial das suas famílias conservou padrões ao longo do tempo, de modo que, ainda hoje, os descendentes dos escravos relacionados a estes senhores residem nas regiões identificadas pelos rios, as quais eram por estes dominadas. Os escravos dos Nunes se localizavam na região dos rios São Gorgonho e Faxinalzinho, os escravos dos Monteiro estavam localizados na região do rio Josafaz e os escravos dos Fogaça localizavam-se na região do rio Mampituba. Desse modo, como referem os autores, as regiões identificadas pelos rios configuram um parâmetro territorial de grande alcance, que divide a comunidade São Roque em extensões de terras e, para cada uma das regiões identificadas há especificações e critérios de subdivisão, conhecidos como o sistema das grotas. Sobre as origens desse sistema de organização, para o membro da comunidade Valdomiro Oliveira:

Ninguém demarcava terra, era tudo terra em comum. A divisão era de grota em grota. Todos moravam naquelas beira de sanga e cultivavam. Bem dizer a divisa era os bicos dos morros. Toda nossa região só tem, no máximo, dez por cento de terra para agricultura. 0 pessoal desceu e se acomodou nas grotas, cada um com a sua área. As grotas têm nome. Cada família se acomodava em uma grata (sic). Nunca teve discussão por causa das grotas. Discussão houve quando veio gente de fora. (Fernandes e cols., 2016:162).

0 estudo elaborado por Fernandes e cols. (2006) remonta às origens dessa comunidade, 0 que auxilia na compreensão de costumes e formas de interação que se estabeleceram e são ainda mantidos entre estes descendentes dos escravos que habitavam a região. Uma vez que os quilombos no Rio Grande do Sul mantiveram uma tradição de pequeno porte, os autores explicam que os quilombos não se constituíam isoladamente, mas por meio de uma rede de 
relações, que envolvia comunicação, trocas, comércio e ajuda mútua. Sobre esta configuração, para eles: "[...] é possível supor que Campo dos Pretos e São Roque tenham configurado no século XIX uma forma conjunta de reprodução econômica e cultural, parte de um sistema de resistência que unia mais de um núcleo populacional." (Fernandes e cols., 2006:150). Nessa dinâmica, conforme os autores, os documentos históricos evidenciam que a região de Cima da Serra se constituiu em um reconhecido destino para fugas, atraindo, inclusive, pessoas de outras regiões, que chegavam a partir desse sistema de informações, fomentado pela solidariedade em função da vivência em comum da escravidão.

No período de escravidão na região, configurou-se um ambiente caracterizado pela natividade dos escravos e pela coabitação entre escravos e senhores, conforme apontam os autores com base em documentos históricos. Tais particularidades conformaram complexas relações de domínio, pois, embora desde muito nova a criança sofresse as amarguras da liberdade cerceada, ia também desenvolvendo estratégias para obter benefícios de sua condição. "Trata-se de um sistema de domínio que possibilita diferentes formas de inserção do escravo na sociedade local e regional." (Fernandes e cols., 2006:143). Disso, resultavam conhecimentos sobre a região, os caminhos, a geografia e a história do lugar, que seriam fundamentais para o escravo no caso de uma fuga, fato este que exigia dos senhores a manutenção de algumas concessões a fim de manter o domínio senhorial. Outra particularidade observada nessa região era o grande número de pais e filhos escravos pertencentes ao mesmo senhor ou a mesma família. Em conjunto, esses aspectos conformaram uma relação de domínio marcada por algum grau de confiança, o que autorizava certa mobilidade a esses escravos nas fazendas de São Francisco de Paula.

Tornou-se um costume dos senhores mandarem seus escravos da região serrana para a região litorânea a fim de cultivarem as terras da localidade conhecida como Roça da Estância, complementando, assim, a produção das estâncias. Nessa área, segundo os autores, escravos e trabalhadores livres permaneciam uma parte do ano, cuidando da lavoura, e, após a colheita, a produção era levada para Cima da Serra. Na narrativa do membro Pedro de Oliveira Pereira:

Meu pai contava que esses carreiro de serra foram abrido descoberto pelos carreiro de anta e carreiro de tigre, e daí os trabalhador iam abrindo os carreiro porque diz que o tigre e a anta não subia perau. Daí aqueles habitante daqui que eram escravos trabalhavam para os senhor lá da serra, que tudo era fazendeiro, a mãe contava que botavam alças assim nos ombro e botavam outras coisas assim na testa para resistir o peso para subir na serra para levar aqueles mantimento (...) eram carregados nas costas, como depois nós usava os cargueiro de mula. (Aguiyrre \& Cardoso, 2008).

$\mathrm{Na}$ perspectiva de Fernandes e cols. (2006), tais aspectos são importantes para entendermos a dinâmica social e populacional que caracteriza a comunidade quilombola de São Roque, pois a mobilidade dos escravos fugidos, desertores e outros fugitivos na região irá gerar a flutuação da população quilombola. Segundo seus estudos, mais de 60 famílias compõem a Associação Remanescente de Quilombos de São Roque, embora apenas 26 famílias residam na comunidade; por razões a seguir referidas, as demais famílias vivem espalhadas pelas cidades e em zonas rurais da região. A característica da mobilidade fica explícita nas narrativas da comunidade a respeito desse constante deslocamento, como destacam os autores, seja pelo esgotamento da capacidade produtiva da região, seja pelas enchentes que assolaram Pedra 
Branca, o "[...] ir e vir, passar épocas da vida em alguma cidade de Cima da Serra ou do litoral trabalhando para outros marca a trajetória dessas pessoas." (Fernandes e cols., 2006:154).

Desse modo, os critérios de pertencimento à comunidade não estão limitados a noções exclusivas de residência. Como esclarecem os autores, "Tais critérios foram sendo estruturados em torno da ancestralidade negra, do parentesco comum e da condição de 'filhos da Pedra Branca', em oposição àqueles que possuem terras no local, porém, são 'de fora'." (Fernandes e cols., 2006:136). É comum moradores da comunidade trabalharem para esses "de fora", os "fazendeiros" ou "chacareiros". Em sua fala, Maria Rita Dutra explica sobre o pertencimento de um dos membros, que ele não é "moreno", mas é filho de Pedra Branca, pois "[...] os pais dele nasceram ali". Como discutem os autores, o fato de "[...] ser 'filho de Pedra Branca' pressupõe não apenas ter nascido, morado no local ou ser parente, mas ter a comunidade e o espaço físico como lugar de pertencimento." Tal condição se contrapõe, àquela de explorador, de recursos naturais e humanos, como é o caso dos "de fora", que não partilham das práticas locais. Segundo Fernandes e cols. (2006:136-137):

Para fazer parte da comunidade, então, é preciso estar inserido em uma série de práticas, dentre as quais: convidar o "compadre" para um trabalho fora numa época de entressafra; pegar uma "empreitada" junto; respeitar as divisões territoriais implicadas pelo "sistema de grotas"; partilhar conhecimentos como aqueles referentes ao acesso a direitos, como a previdência rural; dar uma carona ou emprestar um animal; fazer o almoço para aqueles que participam do sistema do "troca dia" de trabalho.

Nesse sentido, os autores ressaltam que, mesmo os que não moram na localidade, mas são considerados parte da comunidade, têm como projeto retornar para o local. 0 que leva à compreensão de que a noção de pertencimento à comunidade é construída a partir de vários critérios positivos, que vão desde as vantagens do clima para a agricultura, até a valorização dos vizinhos, da liberdade e dos recursos. Perspectiva, esta, bem diversa daqueles que não são membros da comunidade e definem a Pedra Branca como um local afastado e sem estrutura, "[...] com uma conotação de espaço marginal ou pobre.” (Fernandes e cols., 2006:136). Significações como espaço de refúgio e de liberdade emergem nas falas dos membros da comunidade sobre o lugar. Nas palavras de Valdomiro de Oliveira:

Foi aqui que a nossa descendência veio se esconder naquela época, mas não foi se esconder, foi quando eles ganharam a liberdade, como se diz, e daí os senhor deles disseram assim, agora vocês não pode ser mais escravo, nós não podemo manter vocês, vão pra lá, vão se virar, então eles acharam essas posses aí e tudo "de varde", tudo mataria, daí eles entraram para lá e vieram abrindo espaço. (Aguiyrre \& Cardoso, 2008).

A liberdade constitui-se em valor fundamental para essas pessoas, mobiliza e pauta suas ações no presente, tendo como inspiração os exemplos de luta e de resistência de seus ancestrais. E o espaço construído por eles nesta comunidade representa esse espaço de liberdade, o lugar em que podem "se governar", que ainda hoje é constantemente desrespeitado e ameaçado. Como pontua o membro da comunidade Dílson Nunes:

e daí ficamos ali, parado, não podemos se mexer... aqui, andamos de noite, andamos de dia; na praça não podemos nos mexer. Na praça, se tiver dinheiro é perigoso e, se não tiver, é perigoso do mesmo jeito. E, aqui, nós nos cuidamos só 
de cobra. Deus cuida. Não adianta pegar a fotografia do perau, do nosso rancho. Mas, e a nossa liberdade, aonde foi. A liberdade aonde foi? (Fernandes e cols., 2006:178).

Nessa narrativa, ele compara os espaços da cidade e do campo para expressar sentimentos; de bem viver ${ }^{1}$ e pertencimento em relação ao seu lugar, a comunidade São Roque; e o contrário, em relação à praça, como um restrito espaço de sociabilidade representando a cidade. Sob essa perspectiva, as discussões centrais desde a criação da Associação situam-se na titulação do território quilombola e na revisão das restrições ambientais impostas ao sistema produtivo desenvolvido pelas famílias a partir da implantação dos parques. Restrições, estas, que de forma drástica são impostas aos modos de vida e de subsistência dos habitantes do local, como a proibição de colocação de roças novas, de utilização de madeira para reconstrução de casas e a ameaça de expulsão do local. Como exemplificado pelo membro Dilson Nunes, "[...] tem um cunhado do Pedro que andou correndo pra se escapá. Capoeira adentro correndo se escondeu. Não acha que é pior do que a escravidão? Tá correndo porque tá trabalhando? Chega ali com vontade de te chicotear só porque eu tinha feito uma roça pra plantar milho." (Fernandes e cols., 2006:177).

Sobre a questão, no início da década de 1970, as terras da comunidade São Roque passaram a ser alvo do interesse de fazendeiros oriundos da Serra, dos municípios de São Francisco de Paula e Cambará do Sul. Como retomam Fernandes e cols. (2006), as terras e a mão de obra barata constituíam os principais atrativos a estes novos proprietários, conhecidos na comunidade como os "de fora". A entrada dos fazendeiros e a aquisição das terras foram facilitadas pela migração de muitos moradores atingidos pela grande enchente de 1974, que teve um efeito devastador na comunidade, ambiental e socialmente, o que se manifesta nas suas falas e está marcado inclusive no sistema de grotas, a partir de duas nomeações que decorreram deste evento, a grota feia e a grota escorrida. Como relata Maria Rita (identificada como bisneta do escravo Paquê), "a enchente levou a casa onde moravam com tudo, inclusive os mantimentos que garantiam a alimentação da família, e arrasou as roças." (Fernandes e cols.,2006). Passados oito meses na cidade, ao retornarem, deparam-se com um fazendeiro que havia comprado, do seu irmão, parte do direito de posse das terras, no tempo em que "se trocava terra por cavalo". Passaram então a trabalhar em parceria com o fazendeiro, perdendo cada vez mais autonomia e tendo que dividir o fruto do seu trabalho na roça.

Desse modo, como ressaltam Fernandes et al (2006), a enchente marca o momento identificado pela comunidade como o confronto que põe em risco sua unidade, sua reprodução física e cultural, na medida em que a entrada dos "de fora", que hoje são os principais donos de terras no local, configura um novo modo de ocupação das áreas, escasseando as terras produtivas e sujeitando muitos a venderem sua força de trabalho como peões. Além disso, muitos desses fazendeiros, na década de 1980, venderam aos órgãos públicos extensões de terras além daquelas que possuíam, restringindo ainda mais as áreas de moradia e agricultáveis na comunidade, que passaram a ser aquelas confinadas entre as pastagens dos fazendeiros e as

1 "[...] conceito elaborado por antropólogos, juntamente com comunidades tradicionais indígenas e afrodescendentes dos países andinos." (Del Ré, 2014). 
áreas de preservação ambiental. Segundo os autores, as aquisições de terras por parte do órgão ambiental federal apresentaram inúmeras irregularidades e os membros da comunidade sofreram pressões (multas e intimações) para abandonarem suas terras. Também se relaciona a este processo, no mesmo período, a abertura da estrada que liga Pedra Branca ao centro do município de Praia Grande/SC, visto que, até então, não havia uma estrada trafegável e o acesso à comunidade dava-se por picadas na mata, utilizadas por tropas e cargueiros de tração animal. Como reflete Afonso Pereira dos Santos Filho, "[...] a abertura da estrada 'fez a ponte' para a saída dos moradores e a entrada dos 'de fora'." (Fernandes e cols., 2006:173).

Nesse sentido, como destaca Haesbaert (2007:28) quanto à historicidade do território, a variação se dá de acordo com o contexto histórico e geográfico, perpassando pelas diversas fases do capitalismo, de modo que vêm se dissolvendo cada vez mais nas sociedades modernas a dinâmica que prevalecia nas sociedades tradicionais, e que "[...] conjugava a construção material ('funcional') do território como abrigo e base de 'recursos' com uma profunda identificação que recheava o espaço de referentes simbólicos fundamentais à manutenção de sua cultura." $\mathrm{Na}$ comunidade São Roque, a partir dessas interferências e das restrições impostas pelos órgãos estatais aos moradores para a colocação das roças, práticas como a "troca dia" têm se tornado cada vez mais escassas e a redução das hortas e roças tem obrigado esses moradores a priorizar alguns cultivos e a comprar diversos alimentos que antes eram ali produzidos (até mesmo as colheitas de milho e feijão já não são suficientes). Como ressaltado no estudo de Fernandes et al (2006), tradicionalmente, as famílias que compõem a comunidade cultivavam todos os alimentos consumidos e confeccionavam todos os seus utensílios. Ainda hoje, artesanatos locais como o balaio Jacá, confeccionado de taquara ou de cipó, para transportar milho, e as peças em miniatura de cangalho ilustram esses costumes. (Pithan, 2013). Sobre seus costumes, Valdomiro de Oliveira conta que:

As casas eram de parede de pau e barro (barreado) - faz um gradeado e bota barro-chão batido, fogo dentro de casa, o teto era de Pau de Uricanga. A casa era repartida: uma cozinha e um quartinho. Ao lado da casa tinha os galpãozinhos, para botar o milho. Plantavam um pouco retirado por causa da criação dos porcos e das galinhas. Água era nas sangas. Lampião de querosene. Nós fazia vela de cera de abelha. (Fernandes e cols., 2006:163).

No que tange às relações de produção, no modo de ocupação desenvolvido na comunidade, Fernandes et al (2006) destacam que, no sistema de grotas, os moradores se "governavam" dentro de uma vasta área de terras em que figurava a possibilidade de se mover no território, prevalecendo uma agricultura de subsistência e não para a comercialização ou para a venda de força de trabalho. Nos relatos de Salustiano Navarro, "Trabalho só para o sustento. Trabalhei com o Nivaldo Pinto. Ele foi comprando as terras dos outros e depois vendeu para o Ibama. Minha mãe também trabalhava na roça"; e de Paulo Oliveira, "Meu pai trabalhava com plantação, semente de milho, feijão. Plantava para o consumo. Para vender era difícil, colocava nos cargueiros e ia pelo carreiro na beira do rio até a Praia Grande. As sementes ele guardava." (Fernandes e cols., 2006:164). Emerge aí a ideia de sustentabilidade, da semente como potência da raiz, da planta, da manutenção da colheita.

Quanto às relações de solidariedade construídas e mantidas, Fernandes et al (2006) destacam que os cuidados com o outro relacionam-se à própria manutenção da comunidade, visto que a maioria dos membros não possui terras para plantar, dependendo, assim, de relações 
de reciprocidade tecidas, de modo a garantir a permanência daqueles que não possuem terras próprias para a colocação de roças. Como referido por Santos (2000:108), os atores hegemonizados têm no território um abrigo "[...] buscando constantemente se adaptar ao meio geográfico local, ao mesmo tempo que recriam estratégias que garantam sua sobrevivência nos lugares." Ainda, relações de parentesco concebidas e realizadas pelos membros da comunidade São Roque, "[...] não apenas entrelaçam pessoas e histórias, mas articulam noções específicas de territorialidade e sociabilidade." (Fernandes e cols., 2006:156). Identificam-se, assim, por meio de suas narrativas, referências de organização social e territorial que remontam ao "tempo dos escravos" e são por eles cultivadas e respeitadas. Na análise dos autores, o sistema de parentesco estabelecido caracteriza-se por três principais aspectos: endogamia local, com incorporação de afins (assinaturas) 'de fora'; descendência familiar englobada por foco no tempo dos escravos; e residência com predomínio de famílias extensas sobre sistema de grotas. Além do sistema das grotas, que abrigam tanto residências quanto áreas para o cultivo e para a criação de animais, outro padrão tradicional de divisão de terras conservado entre as famílias da comunidade São Roque constitui as Seções Comunitárias, Josafaz e Faxinalzinho, que, formadas a partir de parâmetros de organização e divisão social do trabalho, articulam arranjos de produção que envolvem diferentes famílias, de diferentes grotas. Como define Valdomiro de Oliveira, "Aqui nós trocamos dia de serviço, é o sistema dos antigos. Tinha dias que trabalhávamos de 12. Era união como se diz." (Fernandes e cols., 2006:166). Assim, o trocar dia de serviço constitui um sistema que preserva práticas colaborativas, reunindo, em uma grota, trabalhadores de diferentes grotas, como um mutirão, de modo a dar conta das lidas na roça a ser cultivada no dia.

Além dessa cadeia de solidariedade formada no trabalho, as turmas do Josafaz e do Faxinalzinho, tratadas como seções comunitárias pelos autores, sinalizam também a identificação de pertencimentos históricos próprios, visto que cada uma destas seções dispõe de um acervo próprio de histórias, locais e eventos de socialização, caminhos e sítios sagrados. Exemplo disso, são os três cemitérios identificados no estudo: um no rio Josafaz (onde estão sepultados muitos dos Monteiro), um no rio Mampituba (Fogaça) e outro no rio Faxinalzinho (Nunes). As seções Josafaz e Faxinalzinho também possuíam como centros de socialização as raias, onde se reuniam e eram disputadas carreiras. Hoje, a Igreja Católica, construída no centro geográfico e cultural da comunidade, na região entre os rios Josafaz, Mampituba, São Gorgonho e Faxinalzinho, constitui importante espaço comunitário de socialização, concentrando as festividades. Mas são ainda celebradas missas ao ar livre, embaixo de árvores que serviam de igreja (Aguiyrre \& Cardoso, 2008), preservando costumes transgeracionais. Como destacam Fernandes e cols., (2006), a partir da década de 1950, a festa de São Roque se tornou referência comunitária e da região e, o próprio nome da comunidade São Roque surgiu com a construção da igreja. Ainda que preservem os simbolismos católicos, os membros da comunidade contam e reproduzem casos de figuras míticas e lendárias surgidas na comunidade, como o Gritador, um gigante, as bolas de fogo e o tatu de ouro; este último, na visão deles, seria uma manifestação dos escravos mortos por seus senhores após enterrarem os tesouros a seu mando, que "[...] ficavam ali mesmo, daí vinham essas assombrações." (Aguiyrre \& Cardoso, 2008).

Acerca da regulamentação comunitária de São Roque, Fernandes e cols., (2006:169) qualificam como um exemplo radical do seu alcance a classificação entre proprietários e arrendatários reconhecida entre os seus membros. Embora as terras da comunidade não estejam tituladas, essa classificação designa o estatuto ou a qualidade da posse, que, conforme os 
autores informam sobre modos culturalmente específicos de organização territorial e de definição dos limites da comunidade. "Proprietários, afinal, são aqueles que mantêm e reproduzem certas relações tradicionais entre a terra e a comunidade. Arrendatários são aqueles que reconhecem e se submetem a estas relações tradicionais". Na explicação do membro Afonso Pereira dos Santos Filho, sua mulher é nascida e criada no lugar, exatamente naquela grota, então, bem dizer, ela é proprietária. (Fernandes e cols., 2006:175).

A partir dos diversos aspectos abordados nos estudos aqui analisados sobre a Comunidade Quilombola São Roque, destaca-se a resistência como um signo que marca cada um dos seus integrantes. Como refletem Fernandes e cols., (2006:179), "[...] o mencionado instinto de conservação é acionado também quando os moradores se contrapõem ao processo de criminalização a que estão sendo sujeitados não meramente pela necessidade de produção ou de sobrevivência, mas pela valorização de suas práticas como formas de preservação." Segundo a compreensão do membro da comunidade Dílson Nunes, a preservação diz respeito ao homem e à natureza conjuntamente:

A preservação, essa, é muito boa. A Sra. notou, aqui em roda do rancho, nós estamos preservando: fizemos um projeto, no tempo do meu pai, esposo da minha mãe, com meu irmão... nós conversando [...] de plantar mais longe, enquanto estamos mais novos, e depois, quando estivermos mais velhos... temos terra aqui em roda do rancho, derrubamos, plantamos e colocamos as outras pra descansar. Agora, ali, dizem que não pode derrubar mais. (Fernandes e cols., 2006:179).

Tratam-se, assim, de práticas tradicionais, concebidas a partir de saberes construídos por meio de experiências coletivas, que viabilizaram a subsistência dessas famílias com os meios de que dispunham e a reprodução da sua cultura e do seu modo de vida.

\section{Considerações Finais}

A Comunidade São Roque vem ressignificando sua resistência a partir da história de escravidão que levou seus ancestrais a se reunirem nesse espaço de refúgio e de liberdade construído por eles. Como bem definem Leite e Fernandes (2006:11), “[...] o quilombo faz da terra a metáfora que possibilita a continuidade do grupo, expulso de seu habitat e inserido em outro mundo onde a sua condição humana plena lhe foi extraída e negada." Como amplamente discutido, a liberdade representa valor fundamental para esses descendentes de escravos, que lutam por manter o espaço, físico, social e político, no qual convivem e transmitem suas tradições e sua cultura ao longo das gerações. Em sua territorialidade, expressam os aspectos identitários que os distinguem. Mas o seu lugar, onde podem "se governar", vem sendo constantemente ameaçado e desrespeitado, inclusive ao reduzirem-no a valores monetários de indenizações, desconsiderando o efetivo espaço conquistado por esses atores e o patrimônio cultural que representam em seus modos de vida e de interação com a natureza. 0 direito dos 
quilombolas à terra está associado ao direito de preservação de sua organização social, cultura, identidade e pertencimento a sua territorialidade.

No presente estudo, revisitam-se memórias políticas, por meio de dados secundários, face à premência de registrar narrativas e imagens da Comunidade São Roque a partir das epistemologias, cosmologias e saberes situados na própria comunidade, e a partir dela. Esse trabalho teórico e de pesquisa configura-se como um estudo em Psicologia Política, um esforço em reunir informações e conhecimentos que possam dar visibilidade a uma comunidade em processo de conflitos, luta e resistência. Nessa perspectiva, valoriza-se a Comunidade São Roque a partir de suas idiossincrasias e de suas próprias dinâmicas territoriais e, consequentemente, políticas. 


\section{Referências Bibliográficas}

Aguiyrre, Cláudia (direção). (2008). Documentário - Comunidade São Roque - Referências Culturais Quilombolas. Áudio visual. Brasil; Ministério da Cultura; Estado de Santa Catarina. Acessado em 20 de Junho de 2018, de: https://www.youtube.com/watch?v=iOul1DAQPWI

Amaral, Eduardo Antônio Ribas. (1998). Parques e comunidades rurais são compatíveis? Estudo de caso no Parque Estadual da Serra do Tabuleiro. Dissertação (Mestrado em Agroecossistemas) - Universidade Federal de Santa Catarina (UFSC), Florianópolis.

Bonnemaison, Joel. (2012). Viagem em torno do Território. Geografia cultural: uma antologia. (pp. 279-304); Rio de Janeiro: Ed. UERJ. Acessado em 23 de Junho de 2018, de:

https://books.google.com.br/books?hl=ptBR\&lr=\&id=IuGvDgAAQBAJ\&oi=fnd\&pg=PA 279\&dq=BONNEMAISON,+Joel.+Viagem+em+torno+do+Territ\%C3\%B3rio\&ots=Dy6L $\underline{04 \mathrm{Vt} 9 \mathrm{e} \& \operatorname{sig}=\mathrm{DxpzIvZv2tFHCtai8WMbpCUjGTA \& redir} \mathrm{esc}=\mathrm{y} \# \mathrm{v}=\text { onepage } \& \mathrm{q}=\text { desaparec }}$ $\underline{\mathrm{er} \& \mathrm{f}=\mathrm{false}}$

Brasil. (1998). Constituição da República Federativa do Brasil. São Paulo: Saraiva.

Correa, Roberto Lobato. Territorialidade e Corporação: Um Exemplo. Em M. Santos, M.A. Souza, M.L, Silveira (Org.). Território Globalização e Fragmentação. São Paulo, Hucitec, 1994.

Decreto n. 4.887. (2003, 20 de novembro). Regulamenta o procedimento para identificação, reconhecimento, delimitação, demarcação e titulação das terras ocupadas por remanescentes das comunidades dos quilombos de que trata o art. 68 do Ato das Disposições Constitucionais Transitórias. Brasília, DF: Presidente da República. Acessado em 23 de Junho de 2018, de: http://www.planalto.gov.br/ccivil 03/decreto/2003/d4887.htm.

Del Ré, Mégui F. (2014). Comunidades remanescentes de quilombos, bem viver e a política de desenvolvimento territorial rural na zona sul do Rio Grande do Sul. Dissertação de Mestrado. Universidade Federal do Rio Grande do Sul, Porto Alegre.

Fernandes, Ricardo Cid., Brustolin, Cindia., \& Teixeira, Luana. (2006). Relatório Antropológico: A comunidade São Roque. Boletim Informativo NUER, Florianópolis, 3(3), 131-186.

Furlan, Sueli A. (2000). Lugar e cidadania: implicações socioambientais das políticas de conservação ambiental (situação do Parque Estadual de Ilhabela na Ilha de São Sebastião - SP). Tese (Doutorado em Geografia) - Faculdade de Filosofia, Letras e Ciências Humanas, Universidade de São Paulo, São Paulo.

Haesbaert, Rogério. (2004). Dos Múltiplos Territórios à Multiterritorialidade. Porto Alegre. Acessado em 23 de Junho de 2018, de: http://www6.ufrgs.br/petgea/Artigo/rh.pdf

Haesbaert, Rogério. (2017). Território e multiterritorialidade: um debate. GEOgraphia. IX(17), 19-46.

Lei $n^{\circ}$ 9.985. (2000, 18 de julho). Lei institui o Sistema Nacional de Unidades de Conservação da Natureza - SNUC. Acessado em 23 de Junho de 2018, de: http://www.planalto.gov.br/ccivil_03/Leis/L9985.htm

Leite, Ilka Boaventura., \& Fernandes, Ricardo Cid. (2006). Fronteiras territoriais e questões teóricas: a antropologia como marco. Boletim Informativo NUER, 3(3), 7-14.Leite, Ilka Boaventura. (1991). Descendentes de Africanos em Santa Catarina: invisibilidade histórica e segregação. Textos $e$ Debates, 1(1), 5-42. 
Leite, Ilka Boaventura. (1991). Terras e territórios de negros no Brasil, em textos e debates. Núcleo de estudos sobre identidade e relações interéticas. I(2), 39-46. Disponível em: Acessado em 23 de Junho

de

2018

de: https://repositorio.ufsc.br/bitstream/handle/123456789/126236/Textos\%20e\%20Debates\%20No\%2 02.pdf? sequence $=2 \&$ is Allowed $=\mathrm{y}$

Lifschitz, Javier Alejandro. (2014). Os agenciamentos da memória política na américa latina. Revista Brasileira de Ciências Sociais, 29 (85), 145-158. Acessado em 23 de Junho de 2018, de: https://dx.doi.org/10.1590/S0102-69092014000200010

Little, Paul E. (2002). Territórios sociais e povos tradicionais no Brasil: Por uma antropologia da territorialidade. Série Antropologia, (pp. 322, Brasília.

Massola, Gustavo M., Santos, Alessandro O., \& Martins, Alessandra. (2015) Turismo de base comunitária: instrumento para o fortalecimento da gestão democrática em quilombos no Brasil. Em Mitsuru Higuchi Yanaze; Felipe Chibas Ortiz; Kleber Markus. (Org.). Marketing e comunicação de projetos socioculturais: experiências brasileiras e cubanas. 01ed. (pp. 279-303). São Caetano do Sul/SP: Difusão Editora.

Pithan, Saulo. (2013). Comunidade Quilombola - Praia Grande (parte 1). ARTV Canal 5. Áudio visual. Acessado em 23 de Junho de 2018, de: https://www.youtube.com/watch?v=3QS9shcTiwYReis, João José. (1996). Quilombos e revoltas escravas no Brasil. Revista USP, 28, 14-39.

Santos, Milton. (1994). O Retorno do Território. Em Milton Santos, Maria A. Souza., \& MariaL, Silveira (Org.). Território Globalização e Fragmentação. São Paulo, Hucitec.

Santos, Milton e Cols. (2000). O papel ativo da geografia: um manifesto. Revista Território, V(9), 103-109. Acessado em 23 de Junho de 2018, de: http://www.revistaterritorio.com.br/pdf/09 7 santos.pdf

Santos, Milton., Souza, Maria Adélia de., \& Silveira, Maria Laura. (1998). Território: globalização e fragmentação. 4. ed. São Paulo: Hucitec: ANPUR.

Saquet, Marcos Aurelio (Org.). (2009). Por uma abordagem territorial. Saquet, Marcos Aurelio (Org.); Sposito, Eliseu Savério (Org.). Territórios e territorialidades: teorias, processos e conflitos. São Paulo: Expressão Popular.

Silva, Sandro José da. (2006). Quilombolas no Espírito Santo: identidade e territorialidade. Revista Dimensões, 18, 272-300. Acessado em 23 de Junho de 2018, de: http://www.periodicos.ufes.br/dimensoes/article/view/2448

Spaolonse, Marcelo Barbosa. Desamparados nas grotas do estado: os contratempos da sobreposição entre o território quilombola de São Roque e os Parques Nacionais de Aparados da Serra e da Serra Geral. Revista do Centro de Estudos Rurais - RURIS (UNICAMP), Campinas, 7(2), 33-56, set. 2013 